\title{
DYNAMICS OF PROCESS CONSTITUENT REPRESENTATION OF SPORTS EVENT IN DIACHRONIC CORPUS ${ }^{1}$
}

\author{
Elena Yu. Ilyinova \\ Volgograd State University, Volgograd, Russian Federation \\ Larisa A. Kochetova \\ Volgograd State University, Volgograd, Russian Federation
}

\begin{abstract}
The article presents an overview of opinions on Corpus linguistics, methodology of corpus researches is discussed in synchronic and diachronic perspectives, and the corpus statistical tools are discussed as a means to reveal the thematic organization of the text and build a cognitive-and-discursive model to describe a genre prototype for a group of texts. Corpus linguistics tools are applied to the compiled diachronic corpus of news texts about sports events at Olympiads in 1908 and 1948 (retrieved from "The British Newspaper Archive" with 46552 and 63093 words per sub-corpus). Categorization of the process for sports event was carried out with the support of AntConc that allowed to extract lists of words for each sub-corpus, reconstruct semantic means of process representation, identify the lock words that represent the sports event in the two sub-corpora. Having compared the key words from the 1948 sub-corpus with the 1908-referential-sub-corpus, the researchers hold cognitive-and-semantic analysis of verbs and highlighted semantic peculiarities in representation of sports events in every period; some dynamic changes were discovered, including a growing number of verbs that give a detailed description of the sports event (verbs of movement, acts and activity, physical and emotional states, modus verbs that pointed to low-efficiency of efforts and acts). The data prove efficiency of statistic tools in modeling the topic nuclei and distinguishing prototypical semantic content for a group of texts that belong to one genre but were written in different historical periods. Generalization of the data can open a route to a cognitive-and-discursive model of a genre and help in distinguishing historical and cultural peculiarities of its realization in discourse.
\end{abstract}

Key words: corpus linguistics, event, diachrony, key word, frequency, English.

Citation. Ilyinova E.Yu., Kochetova L.A. Dynamics of Process Constituent Representation of Sports Event in Diachronic Corpus. Vestnik Volgogradskogo gosudarstvennogo universiteta. Seriya 2, Yazykoznanie [Science Journal of Volgograd State University. Linguistics], 2017, vol. 16, no. 2, pp. 47-57. (in Russian). DOI: https:// doi.org/10.15688/jvolsu2.2017.2.5.

УДК $81-11: 811.111$

Дата поступления статьи: 16.01.2017

ББК 81.432 .1

Дата принятия статьи: 24.04.2017

\section{Д ДИНАМИКА РЕПРЕЗЕНТАЦИИ ПРОЦЕССУАЛЬНОЙ СОСТАВЛЯЮЩЕЙ СПОРТИВНОГО СОБЫТИЯ В ДИАХРОНИЧЕСКОМ КОРПУСЕ ${ }^{1}$}

\author{
Елена Юрьевна Ильинова \\ Волгоградский государственный университет, г. Волгоград, Российская Федерация \\ Лариса Анатольевна Кочетова \\ Волгоградский государственный университет, г. Волгоград, Российская Федерация
}

Аннотация. В статье дается критический обзор взглядов лингвистов на корпусную лингвистику, рас-
сматриваются методологические аспекты корпусных исследований в синхронии и диахронии, обсуждается
ценность статистических приемов при анализе корпусного материала с целью выявления общих закономер-
ностей тематической организации текста и создания когнитивно-дискурсивной модели, характеризующей 
смысловую организацию группы текстов единой жанровой отнесенности. На материале корпуса текстов новостных заметок о спортивных соревнованиях на олимпиадах 1908 и 1948 гг, составленного на основе электронного архива британской региональной прессы «The British Newspaper Archive», с помощью программного обеспечения AntConc были построены списки слов для каждого из подкорпусов, проведена реконструкция средств репрезентации процессуальности спортивного события, выявлено тематически стабильное семантическое ядро текстов, представляющих спортивное событие в двух англоязычных новостных подкорпусах. Выделение ключевых глагольных лексем в подкорпусе 1948 г. в сопоставлении с референциальным подкорпусом 1908 г. позволило провести последовательный когнитивно-семантический анализ глагольных единиц, установить семантические особенности детализации спортивных событий в каждый из периодов, выявить динамические изменения в аспекте диахронии, проявившиеся в увеличении в 1948 г. числа глаголов, конкретизирующих процессуальность спортивных соревнований (глаголы движения, разнообразных действий, физических ощущений, эмоциональных состояний, модусные глаголы, указывающие на недостаточность усилий и спортивных действий). Приведенные данные свидетельствуют об эффективности использования инструментов статистического анализа для моделирования тематического ядра и семантического наполнения группы текстов, относящихся к одному жанру, но написанных в разные исторические периоды. Их систематизация делает возможным моделирование когнитивно-дискурсивного каркаса жанра и уточнение историко-культурных закономерностей его реализации в дискурсивной практике.

Ключевые слова: корпусная лингвистика, событие, диахрония, ключевое слово, частотность, английский язык.

Цитирование. Ильинова Е. Ю., Кочетова Л. А. Динамика репрезентации процессуальной составляющей спортивного события в диахроническом корпусе // Вестник Волгоградского государственного университета. Серия 2, Языкознание. -2017. - Т. 16, № 2. - C. 47-57. - DOI: https://doi.org/10.15688/jvolsu2.2017.2.5.

\section{1. Введение}

Корпусная лингвистика как самостоятельная языковедческая дисциплина является сравнительно молодым и интенсивно развивающимся направлением науки о языке, однако определяется она неоднозначно: а) как область лингвистических исследований, основанная на применении компьютерных технологий для статистической обработки текстовой информации; б) как один из методов, позволяющий верифицировать лингвистические теории и гипотезы, а также выявлять новые языковые факты, которые достаточно затруднительно идентифицировать обычными эмпирическими методами. Указанные различия во взглядах на цели и задачи корпусной лингвистики отражены в тематике научных споров о том, является ли она научной парадигмой, подходом, дисциплиной, теорией [Leech, 1992, p. 106; Stubbs, 1993, p. 2f] или инструментом, методологией [McEnery, Wilson, 2001; Meyer, 2002]. В качестве отличительных характеристик корпусной лингвистики ученые называют ее эмпирический характер, ориентацию на изучение «языка в употреблении», использование компьютерных программ обработки корпуса и статистические методы исследования, полагая, что это обосновывает целесообразность ее выделения в ка- честве самостоятельного направления, позволяющего в сочетании с другими подходами и методами лингвистики решать специфические группы лингвистических задач.

В отечественной традиции корпусная лингвистика определяется как дисциплина или раздел прикладной лингвистики, занимающийся разработкой принципов построения и использования лингвистических корпусов (корпусов текстов). Вместе с тем в зарубежной литературе корпусная лингвистика соотносится прежде всего с использованием репрезентативного и сбалансированного аннотированного лингвистического корпуса, снабженного программным обеспечением для извлечения и статистической обработки лингвистически релевантной информации [McEnery, Hardy, 2011]. Под языковым корпусом текстов понимают «большой, представленный в машиночитаемом виде, унифицированный, структурированный, размеченный, филологически компетентный массив языковых данных, предназначенный для решения конкретных лингвистических задач» [Захаров, Богданова, 2011, с. 7].

Корпусные технологии имеют обширные практические области применения: лексикографическая практика, переводоведение, лингводидактика, создание терминосистем, тезаурусов и др. В настоящее время развиваются такие на- 
правления лингвистического знания, как корпусная семантика, корпусный синтаксис, корпусный анализ дискурса, корпусная стилистика, когнитивная корпусная лингвистика, которые не противопоставляются традиционному лингвистическому знанию и методам исследования, а дополняют классические подходы надежными инструментами верификации гипотез, преодолевая субъективизм интерпретативных качественных методов, основанных на интуиции, и полагаясь на точность и объективность математических данных [Валова, Слюсарь, 2016; Шилихина, 2014; Corpora in Cognitive Linguistics..., 2007; Kibrik, Krasavina, 2002; Stefan, 2009].

\section{2. Корпусная лингвистика}

\section{как основа данных о статическом \\ и динамическом состоянии языка}

Поскольку корпусная лингвистика ориентирована на фиксацию реальной картины функционирования языка в его устном или письменном модусе [Кибрик, 2003; Плунгян, 2008, c. 14], в основе научной дискуссии лежит ставший классическим вопрос о том, что изучает лингвистика - язык или речь, математически строгую системность языка или речевую практику, представленную в момент ее порождения (выражения) или зафиксированную в форме текста. Сегодня отечественные ученые склоняются к компромиссному мнению: пора отказаться от постановки вопроса, приводящей к противопоставлению языка и речи. Любые направления современной лингвистики, базируясь на постулатах классической теории языка, занимаются анализом особенностей актуализации единиц языка. Не отвергая постулатов традиционной лингвистики, корпусная лингвистика опирается на корпус языковых фактов как собрание конкретных проявлений языка в речи и изучает закономерности употребления единиц языка в разных модусах речи [Gilquin, Gries, 2009]. Некоторые отечественные исследователи убеждены в том, что «современная лингвистика должна стать лингвистикой корпусов» (см., напр.: [Борискина, 2015]). При этом они не только используют корпусные методы анализа, но и создают корпусы и системы аннотаций корпусных ресурсов (см.: [Баранов, 2003; Плунгян, Сичинава, 2004]), позволяющие осуществ- лять поиск эмпирического материала при помощи поисковых запросов.

Особой сложностью отличаются когнитивные исследования дискурса, основанные на корпусных данных устной или письменной речи. Изучая взаимосвязь человеческого языка и сознания, когнитивная лингвистика активно интересуется изучением семантики слов [Голубкова, 2012; Методы..., 2015 и др.], семантических характеристик синтаксических моделей, организации клаузы; анализируются схематичность и смысловое наполнение конструкций, каузативность, транзитивность, фокусность и информационная сложность устных высказываний и письменных текстов [Кибрик, 2003; Колокольникова, 2010; Kibrik et al., 2002 и др.].

Логично предположить, что методы корпусного анализа будут плодотворными и в когнитивной лингвистике. Российская когнитивная лингвистика ищет пути интеграции с корпусной с целью «разработать интегрированную методологию в двух современных парадигмах - когнитивной и корпусной» [Борискина, 2015, с. 24], уточняет вопросы методологии когнитивного анализа семантики слова на основе компьютерно-корпусных исследований [Методы..., 2015]. Отдельные авторы обосновывают релевантность выбора приемов корпусной лингвистики для когнитивно-семантического анализа с привлечением данных национальных корпусов разных языков. В частности, с помощью сопоставления корпусных данных были установлены особенности синонимического варьирования фразовых глаголов в двух вариантах английского языка (британском и американском) [Голубкова, 2012]. Ни сведения из словарей, ни интроспекция носителей языка не смогли стать надежным источником информации об особенностях употребления фразовых глаголов, параллельно функционирующих в британском и американском английском. Размышляя о целесообразности использования корпуса и обоснованности выводов корпусного анализа, автор указанной работы затрагивает проблему «степени корпусности» исследований, уточняет соотношение понятий «значение» и «употребление», частотности и совстречаемости элементов в дискурсе, подчеркивает значимость смещения фокуса исследования лексики со слова к синтаксической конструк- 
ции и связанной с этим необходимости «инвентаризации» конструкций.

\section{3. Корпусная методология \\ в диахронических дискурсивных исследов ания х}

В последнее время корпусная методология используется не только для изучения синхронного состояния языка, но и для выявления диахронических изменений на различных языковых уровнях, как правило, лексическом, грамматическом и синтаксическом; исследователи также обращаются к проблеме исторической вариативности жанров, регистров, региональных вариантов языка (см.: [Соловьев, 2012; Diachronic Corpora..., 2016]).

Диахронический подход к языковому материалу нацелен на обнаружение вариативности в функционировании языковых феноменов на временной шкале, что предполагает использование сопоставимых корпусов текстов и обращение к квантитативным методам мониторинга, принятым в корпусной лингвистике. При этом становится возможным изучение особенностей функционирования языка в разные исторические периоды, что открывает путь к реконструкции языковой системности отдельного периода, выявлению ее семантических, грамматических, синтаксических, стилистических и риторических особенностей, а также установлению жанровой и дискурсивной специфики речевой практики в тот или иной период.

Для решения указанных задач диахронические исследования в корпусной лингвистике опираются на использование одного корпуса, включающего тексты, созданные в различные периоды истории языка, двух или нескольких подкорпусов, содержащих тексты одного или различных жанров, но относящихся к разным периодам функционирования языка, различных корпусов, содержащих тексты сопоставимых жанров.

Корпусно-ориентированные исследования позволяют изучать различные аспекты актуализации языка в целом или в его конкретном национально-культурном проявлении, в том числе грамматическую, семантическую, стилистическую, социолингвистическую и другие виды языковой вариативности, определять тенденции развития языка на основе анализа дис- курсивных практик в синхронии и диахронии. Достоверность данных опирается на методы математической статистики, заложенные при создании систем корпусов текстов. Программное обеспечение аннотированных лингвистических корпусов позволяет лингвистам выбирать из существующего набора статистические критерии (меры), релевантные для решения исследовательских задач в области морфологии, синтаксиса, семантики, стилистики, теории дискурса, когнитивной лингвистики и других областей лингвистического знания. К числу наиболее распространенных статистических мер, которыми располагает, например, такой прототипный корпус, как $B N C w e b$, относятся: абсолютная и нормализованная частотность, коэффициент взаимной информации (mutual information), куб взаимной информации (MI3), Т-критерий (T-score), Z-критерий (Z-score), метод максимального правдоподобия (log-likelihood), коэффициент Дайса (Dice), Log Ratio и др. [Hoffmann et al., 2008]

Отметим, что из-за недостаточной обоснованности возможностей применения статистики для изучения языка и трудностей в интерпретации статистических мер в поле гуманитарного знания ученые указывают на проблемность в обосновании выбора статистических мер, адекватных для описания конкретных фактов функционирования языка. Однако в корпусной лингвистике сложились алгоритмы применения статистических методов анализа изучаемых единиц, релевантные для той или иной проблемной области (см., напр., [Ellis, 2002; Захаров, Богданова, 2011] и др.), что позволяет получить надежные и достоверные данные, которые можно легко верифицировать при условии использования одного и того же материала исследования и компьютерной программы.

\section{4. Реконструкция процессуальной составляющей новостных текстов в диахроническом корпусе}

$\mathrm{C}$ опорой на представленные положения корпусной лингвистики нами была составлена программа когнитивно-дискурсивной реконструкции спортивного события в историко-дискурсивном аспекте. Материалом исследования стал корпус текстов новостных сообщений об олимпиадах, проходивших в Великобритании в 
1908 и 1948 гг., составленный на основе архива британской прессы «British Newspaper Archive» [http://britishnewspaperarchive.co.uk] (общий объем - 46552 слова и 63093 слова соответственно). Задача исследования заключалась в установлении динамики репрезентации когнитивно-дискурсивных закономерностей освещения спортивного события на основе сопоставления семантических данных подкорпусов текстов, относящихся к двум указанным историческим периодам. При проведении исследования статистические данные были получены с помощью программного обеспечения AntConc [Anthony, 2014]. (Некоторые результаты peaлизации программы представлены в: [llyinova, Volkova, 2015].)

Цель данной статьи - реконструировать процессуальность как одну из когнитивно-семантических категорий спортивного события.

Категория процессуальности была выбрана в качестве предметной области анализа спортивного события, поскольку событийность в английской картине мира ассоциируется с динамичным характером бытия: event - «a thing that happens, a planned public or social occasion, one of the races or competitions in a sports program» ${ }^{2}$. Процессуальный признак «to take place as a result of smth» предполагает наличие лица, совершающего действия (напр., спортивные движения и действия), и результатов совершенных действий (личные достижения, победы). При интерпретации информации о процессуальности спортивного события в фокусе внимания оказываются глаголы, которые организуют предложения синтаксически и семантически. Сравнение их реализаций в текстовом пространстве с единым тематическим фокусом «Olympic Games» позволило установить специфику процессуальности в каждом из двух подкорпусов текстов.

В подкорпусах текстов сообщений о спортивных соревнованиях на олимпиадах в 1908 и 1948 гг. было отобрано 75 глаголов, характеризующих процессуальность спортивного события. На основе категориальных признаков «действия», «состояния», «отношения» в границах двух периодов создания текстов они были распределены по нескольким классам и группам: динамические, статальные, релятивные, модусные (функторные), фра- зовые (используются классификационные признаки по: [Винник, 2016, с. 47-49]).

В таблице 1 представлены названия категориальных классов и подклассов процессуальности, обозначающих разные типы спортивных событий, показано распределение глаголов по тематическим группам, в колонке примеров приведены индексы частотности в двух подкорпусах. Отсутствие единицы в отдельном подкорпусе обозначено «ххх». Группы динамических глаголов (Д) доминируют в нашем материале - 15 групп, 62 глагольные единицы (83 \%), остальные группы представлены малым количеством единиц: статальные (C) - 2 группы, 5 единиц (суммарно $13 \%$ ), релятивные (Р) и модусные (М) по 1 группе, 4 единицы (суммарно 4 \%).

Приведенные в таблице 1 данные свидетельствуют о формировании общего тематически стабильного ядра текстов, представляющих спортивное событие в англоязычном новостном контексте, при этом отмечается тенденция увеличения числа глаголов, детализирующих процессуальность спортивных соревнований не только в аспекте действий и движений, но оценочно-образного восприятия и репрезентации в новостном тексте.

В целях выявления диахронической динамики процессуальности при описании спортивного события был использован метод ключевых слов, широко востребованный в корпусной лингвистике. Под ключевыми словами понимаются лексемы, частотность которых в исследуемом корпусе гораздо выше по сравнению с данными референциального корпуса. Поскольку нас интересуют диахронические изменения в дискурсивной репрезентации процессуальности, в качестве референциального корпуса для извлечения ключевых глагольных лексем корпуса 1948 г. использовался корпус 1908 года. Список ключевых слов был построен с учетом статистической меры (log-likelihood), при этом порог отсечения для ключевых слов составил 6,83 . Сопоставление данных подкорпусов позволило проследить динамику ключевых глагольных лексем, определить языковую вариативность текста новостного сообщения о спортивном событии и выявить изменения в характере репрезентации процессуальности при его описании в диахронии. В таблице 2 
Сводные данные о категоризации признаков процессуальности с указанием нормализованной частотности в корпусах 1908 и 1948 гг.

\begin{tabular}{|c|c|c|c|}
\hline Класс & Подкласс & Группа & Примеры \\
\hline \multirow{15}{*}{$\begin{array}{l}\text { Динамические } \\
\text { глаголы (dy- } \\
\text { namic verbs) } \\
62 \text { ед. }\end{array}$} & \multirow{4}{*}{$\begin{array}{l}\text { Глаголы движе- } \\
\text { ния по земле } \\
\text { (movement on } \\
\text { land) }\end{array}$} & Д-1 - бежать & $\begin{array}{l}\text { 1908: } \operatorname{ran}(274.67) \\
\text { 1948: } \operatorname{ran}(202.11), \text { racing }(444.65)\end{array}$ \\
\hline & & $\begin{array}{l}\text { Д-2 - бежать на короткие } \\
\text { дистанции }\end{array}$ & $\begin{array}{l}\text { 1908: sprinted }(51.50) \\
\text { 1948: sprinted }(53.90)\end{array}$ \\
\hline & & $\begin{array}{l}\text { Д-3 - обгонять (бежать с } \\
\text { опережением или следовать } \\
\text { за кем-то, пытаясь вырвать- } \\
\text { ся вперед) }\end{array}$ & $\begin{array}{l}\text { 1908: chase (3), go striding ahead, gain, } \\
\text { overhaul } \\
\text { 1948: chased (13.47), go striding ahead, } \\
\text { gain, overhaul }\end{array}$ \\
\hline & & $\begin{array}{l}\text { Д-4 - ехать (передвигаться } \\
\text { на транспортном средстве, } \\
\text { автогонки, ехать на корот- } \\
\text { кой дистанции) }\end{array}$ & $\begin{array}{l}\text { 1908: rode }(51.50) \\
\text { 1948: rode }(26.95)\end{array}$ \\
\hline & \multirow[t]{2}{*}{$\begin{array}{l}\text { Глаголы движе- } \\
\text { ния по воде } \\
\text { (movement in/by } \\
\text { water) }\end{array}$} & $\begin{array}{l}\text { Д-5 - двигаться по воде } \\
\text { (человек при помощи физи- } \\
\text { ческих движений) }\end{array}$ & $\begin{array}{l}\text { 1908: diving (343.34), rowed (103.00), swam } \\
\text { (51.50), raced (34.33) } \\
\text { 1948: rowed (40.42), swam (53.90), raced } \\
\text { (40.42) }\end{array}$ \\
\hline & & $\begin{array}{l}\text { Д-6-двигаться по воде (при } \\
\text { помощи транспортного } \\
\text { средства) }\end{array}$ & $\begin{array}{l}\text { 1908: rowed (103.00), sailed (34.33) } \\
\text { 1948: sailed (94.32), rowed (40.42) }\end{array}$ \\
\hline & $\begin{array}{l}\text { Глаголы мгно- } \\
\text { венного движе- } \\
\text { ния (momentary } \\
\text { movement) }\end{array}$ & $\begin{array}{l}\text { Д-7 - отрываться от земли } \\
\text { (отталкиваться и быстро } \\
\text { взлетать вверх) }\end{array}$ & $\begin{array}{l}\text { 1908: } x x x \\
\text { 1948: jumped (40.42), leapt (13.47) }\end{array}$ \\
\hline & \multirow{3}{*}{$\begin{array}{l}\text { Глаголы совер- } \\
\text { шения действия, } \\
\text { поступка или } \\
\text { воздействия } \\
\text { (performance } \\
\text { verbs) }\end{array}$} & Д-8 - спортивные действия & $\begin{array}{l}\text { 1908: played (343.34) } \\
\text { 1948: played (269.48) }\end{array}$ \\
\hline & & $\begin{array}{l}\text { Д-9 - готовиться к соревно- } \\
\text { ваниям (готовиться к какой- } \\
\text { то физической активности, } \\
\text { выполняя определенные } \\
\text { физические упражнения) }\end{array}$ & $\begin{array}{l}\text { 1908: } \text { trained }(68.67), \text { prepared }(34.33) \\
\text { 1948: } \text { train }(377.27), \text { prepare }(80.84) \text {, carry } \\
\text { out }(26.95), \text { perform }(53.90)\end{array}$ \\
\hline & & $\begin{array}{l}\text { Д-10 - соревновательная } \\
\text { деятельность (участвовать в } \\
\text { поединках, сражаться с } \\
\text { кем-то, используя физиче- } \\
\text { ские данные) }\end{array}$ & $\begin{array}{l}\text { 1908: meet (326.17), got (309.01), compete } \\
(257.51), \text { scored (223.17), fought (68.67) } \\
\text { 1948: got (256.00), scored (252. 53), meet } \\
(202.11), \text { compete }(148.21) \text {, fought }(94.32)\end{array}$ \\
\hline & \multirow[t]{2}{*}{$\begin{array}{l}\text { Глаголы мгно- } \\
\text { венного действия } \\
\text { (momentary acts) }\end{array}$} & $\begin{array}{l}\text { Д-11 - бросать (касаться } \\
\text { чего-то с применением фи- } \\
\text { зической силы) }\end{array}$ & $\begin{array}{l}\text { 1908: threw (68.67), } \\
\text { 1948: threw (26.95) }\end{array}$ \\
\hline & & $\begin{array}{l}\text { Д-12 - совершать специ- } \\
\text { альные спортивные дейст- } \\
\text { вия (вид спорта) }\end{array}$ & $\begin{array}{l}\text { 1908: } \text { kicked (17.17), shot (274.67) } \\
\text { 1948: shoot (40.42), lifted (40.42) }\end{array}$ \\
\hline & $\begin{array}{l}\text { Глаголы ограни- } \\
\text { ченного действия } \\
\text { (limited activity) }\end{array}$ & $\begin{array}{l}\text { Д-13 - фиксированная точ- } \\
\text { ка начала / окончания дей- } \\
\text { ствия }\end{array}$ & $\begin{array}{l}\text { 1908: began (291.84), finished (274.57), be- } \\
\text { gin, opened (257.51), started (206.01) } \\
\text { 1948: finished (862.32), began (417.39), } \\
\text { started (242.53), opened (175.16) }\end{array}$ \\
\hline & $\begin{array}{l}\text { Глаголы созида- } \\
\text { ния, достижения } \\
\text { нового качества } \\
\text { (resulting activity) }\end{array}$ & $\begin{array}{l}\text { Д-14 - побеждать (быть } \\
\text { лучше остальных, превос- } \\
\text { ходить других в поединках, } \\
\text { соревнованиях) }\end{array}$ & 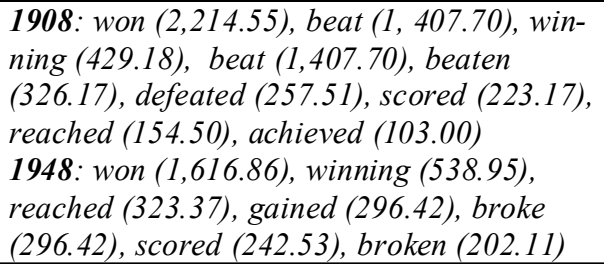 \\
\hline & $\begin{array}{l}\text { Глаголы органи- } \\
\text { зации спортив- } \\
\text { ных мероприя- } \\
\text { тий (organizing } \\
\text { activity) }\end{array}$ & $\begin{array}{l}\text { Д-15 - организовать спор- } \\
\text { тивное мероприятие }\end{array}$ & $\begin{array}{l}\text { 1908: held (772.52), withdrawn (85.84), } \\
\text { qualified (85.84), disqualified (68.67) } \\
\text { 1948: held (660.22), disqualified (363.79), } \\
\text { qualified (323.37), eliminated (148.21), } \\
\text { withdraw (134.74) }\end{array}$ \\
\hline
\end{tabular}


Динамика репрезентации процессуальной составляющей спортивного события

Окончание таблищь 1

\begin{tabular}{|c|c|c|c|}
\hline Класс & Подкласс & Группа & Примеры \\
\hline \multirow{2}{*}{$\begin{array}{l}\text { Статальные } \\
\text { глаголы } \\
\text { (stative verbs) } \\
5 \text { ед. }\end{array}$} & $\begin{array}{l}\text { Глаголы физиче- } \\
\text { ского ощущения } \\
\text { (bodily sensation) } \\
\end{array}$ & $\begin{array}{l}\text { C-1 - ощущения от физиче- } \\
\text { ского действия }\end{array}$ & $\begin{array}{l}\text { 1908: hurt (51.50), feel (51.50) } \\
\text { 1948: felt (53.90) }\end{array}$ \\
\hline & $\begin{array}{l}\text { Глаголы оценки } \\
\text { ощущений }\end{array}$ & С-2 - оценка состояния дел & $\begin{array}{l}\text { 1908: estimated (17.17) } \\
\text { 1948: challenged (121.26), estimated } \\
(107.79)\end{array}$ \\
\hline $\begin{array}{l}\text { Релятивные } \\
\text { глаголы } \\
\text { (relative verbs) } \\
4 \text { ед. }\end{array}$ & $\begin{array}{l}\text { Глаголы компа- } \\
\text { ративности }\end{array}$ & $\begin{array}{l}\text { Р-1 - компаративные / дву- } \\
\text { сторонние отношения, ра- } \\
\text { венство /неравенство }\end{array}$ & $\begin{array}{l}\text { 1908: became (103.00), equaled ( } 34.33) \text {, } \\
\text { equalized (17.17) } \\
\text { 1948: became (161.69), equaled (161.69), } \\
\text { equalised (13.47) }\end{array}$ \\
\hline $\begin{array}{l}\text { Модусные, } \\
\text { функторные } \\
\text { глаголы } 4 \text { ед. }\end{array}$ & $\begin{array}{l}\text { Глаголы, выра- } \\
\text { жающие нереа- } \\
\text { лизованность } \\
\text { действия, недос- } \\
\text { таточность }\end{array}$ & $\begin{array}{l}\text { М-1 - недостаточность уси- } \\
\text { лий в спортивном соревно- } \\
\text { вании }\end{array}$ & $\begin{array}{l}\text { 1908: fell (291.84), failed (137.34) } \\
\text { 1948: failed (229.05), dropped (175.16), col- } \\
\text { lapsed (93.40) }\end{array}$ \\
\hline
\end{tabular}

Таблиия 2

Сравнение статистических данных о ключевых единицах, обозначающих процессуальность, в двух подкорпусах текстов

\begin{tabular}{|c|c|c|c|c|c|}
\hline \multirow{3}{*}{ Глаголы } & \multicolumn{2}{|c|}{1948} & \multicolumn{2}{|c|}{1908} & \multirow{2}{*}{ Mepa Keyness } \\
\hline & $\mathrm{AY}$ & $\mathrm{HU}$ & $\mathrm{AY}$ & $\mathrm{HU}$ & \\
\hline & 1 & 2 & 3 & 4 & 5 \\
\hline upheld & 14 & 188.6 & 0 & 0.0 & 189.6 \\
\hline protested & $\underline{14}$ & 188.6 & 0 & 0.0 & 189.6 \\
\hline$\ldots$ & $\ldots$ & $\ldots$ & $\ldots$ & $\ldots$ & \\
\hline$\ldots$ & $\ldots$ & $\ldots$. & $\ldots$ & $\ldots$ & \\
\hline dismissed & $\underline{13}$ & 175.2 & 0 & 0.0 & 176.2 \\
\hline established & $\underline{12}$ & 161.7 & 0 & 0.0 & 162.7 \\
\hline nominated & 11 & 148.2 & 0 & 0.0 & 149.2 \\
\hline eliminated & $\underline{11}$ & 148.2 & 0 & 0.0 & 149.2 \\
\hline withdraw & $\underline{10}$ & 134.7 & 0 & 0.0 & 135.7 \\
\hline challenged & $\underline{9}$ & 121.3 & 0 & 0.0 & 122.3 \\
\hline retained & $\underline{8}$ & 107.8 & 0 & 0.0 & 108.8 \\
\hline shows & $\underline{7}$ & 94.3 & 0 & 0.0 & 95.3 \\
\hline celebrating & $\underline{7}$ & 94.3 & 0 & 0.0 & 95.3 \\
\hline burn & $\underline{7}$ & 94.3 & 0 & 0.0 & 95.3 \\
\hline occurred & $\underline{6}$ & 80.8 & 0 & 0.0 & 81.8 \\
\hline housed & $\underline{6}$ & 80.8 & 0 & 0.0 & 81.8 \\
\hline cancelled & $\underline{6}$ & 80.8 & 0 & 0.0 & 81.8 \\
\hline broadcasts & 6 & 80.8 & 0 & 0.0 & 81.8 \\
\hline broadcast & $\underline{6}$ & 80.8 & 0 & 0.0 & 81.8 \\
\hline wrenched & $\overline{5}$ & 67.4 & 0 & 0.0 & 68.4 \\
\hline upset & $\underline{5}$ & 67.4 & 0 & 0.0 & 68.4 \\
\hline released & $\underline{5}$ & 67.4 & 0 & 0.0 & 68.4 \\
\hline impressed & $\underline{5}$ & 67.4 & 0 & 0.0 & 68.4 \\
\hline equaled & $\underline{5}$ & 67.4 & 0 & 0.0 & 68.4 \\
\hline disappointed & $\underline{5}$ & 67.4 & 0 & 0.0 & 68.4 \\
\hline burned & $\underline{5}$ & 67.4 & 0 & 0.0 & 68.4 \\
\hline protest & $\overline{41}$ & 552.4 & $\underline{2}$ & 34.3 & 15.7 \\
\hline reported & $\underline{10}$ & 134.7 & $\underline{1}$ & 17.2 & 7.5 \\
\hline
\end{tabular}

представлены ключевые глагольные лексемы подкорпуса 1948 г. с указанием абсолютной (АЧ) и нормализованной (НЧ) частотностей в сравнении с подкорпусом1908 г. и мера Keyness.
В соответствии с таблицей 2 в корпусе 1948 г. ключевыми глагольными лексемами являются upheld, protest (14), dismissed (13), established (12), nominated, eliminated (11), withdraw (10), глаголы upheld, protested об- 
ладают самой высокой мерой Keyness - 189.6. Нулевые показатели в корпусе 1908 г. указывают на отсутствие данных глаголов, что свидетельствует о существенных различиях в приемах описания спортивных событий в двух сравниваемых подкорпусах текстов, выражающихся в значительном увеличении глагольных лексем, не имеющих непосредственного отношения к описанию процессуальности спортивного события. Детальный анализ полученных ключевых слов, отражающий диахронические различия в медийной репрезентации спортивного события, выходит за рамки данной работы и будет продолжен.

\section{5. Выводы}

Несмотря на неоднозначное отношение лингвистов к методам математической статистики в лингвистических исследованиях, представление языковых явлений и фактов в виде набора статистических мер может адекватно отразить специфику функционального использования языковых единиц и способствовать верификации авторской научной гипотезы. Корпусный подход к анализу репрезентативного жанрово и тематически однородного текстового материала, принадлежащего к различным хронологическим срезам, позволил нам установить тематическую системность корпуса по параметру процессуальности, на основе многопараметрического анализа глагольных единиц выявить сходные и различные семантические компоненты текстового тезауруса, отражающего единое событие в медийном дискурсе разной историко-хронологической отнесенности, установить изменения в репрезентации события с помощью динамических глаголов. Дальнейший статистический анализ сочетаемости выявленных глаголов с номинативными единицами позволит реконструировать семантическую сетку текста, описывающего спортивное событие в жанре информационной заметки на английском языке в разные исторические периоды, а обобщение данных по разным периодам даст возможность представить когнитивно-дискурсивный каркас данного жанра и историко-культурные закономерности его реализации в британской традиции медийного дискурса.

\section{ПРИМЕЧАНИЯ}

${ }^{1}$ Исследование выполнено при финансовой поддержке Российского фонда фундаментальных исследований (РФФИ), проект № 15-04-00134 «Историческая дискурсология: проблемы, методология и перспективы развития».

${ }^{2} \mathrm{~B}$ статье приводятся дефиниции из электронной версии толкового словаря английского языка «The Free English Dictionary» (http:// thefreedictionary.com).

\section{СПИСОК ЛИТЕРАТУРЫ}

Баранов, А. Н. Введение в прикладную лингвистику / А. Н. Баранов. - М. : Едиториал УРСС, 2003. $-360 \mathrm{c}$.

Борискина, О. О. Корпусное исследование языка: мода или необходимость? / О. О. Борискина // Вестник Воронежского государственного университета. Серия «Лингвистика и межкультурная коммуникация». - 2015. - № 3. - С. 24-27.

Валова, Е. А. Сравнение корпусного и экспериментального метода на примере исследования синтаксических свойств энклитики же / Е. А. Валова, Н. А. Слюсарь // Компьютерная лингвистика и интеллектуальные технологии : по материалам ежегод. Междунар. конф. «Диалог» (Москва, 1-4 июня 2016 г.). - М. : Изд-во РГГУ, 2016. - Вып. 15 (22). С. 806-816. - Электрон. текстовые дан. - Режим доступа: http://www.dialog-21.ru/media/3438/ valovaeaslioussarna.pdf. - Загл. с экрана.

Винник, Е. И. Функциональная специфика герундия в аспекте лингвогендерологии / Е. И. Винник. - Saint-Louis, Missouri, USA : Science and Innovation Centre Publishing House, 2016. - 202 p.

Голубкова, Е. Е. Дискурсивная составляющая в исследованиях по когнитивной семантике / Е. Е. Голубкова // Вестник Московского государственного лингвистического университета. - 2012. - № 638. C. $90-98$.

Захаров, В. П. Корпусная лингвистика / В. П. Захаров, С. Ю. Богданова. - Иркутск : ИГЛУ, 2011.-161 c.

Кибрик, А. А. Анализ дискурса в когнитивной перспективе : автореф. дис. ... Д-ра филол. наук / Кибрик Андрей Александрович. - М., 2003. - 90 с.

Колокольникова, М. Ю. Дискурс-анализ и корпусный анализ в исследованиях в области исторической дискурсологии / М. Ю. Колокольникова // Известия Саратовского университета. Серия «Филология. Журналистика». - 2010. - Т. 10, вып. 2.-С. 3-6.

Методы когнитивного анализа семантики слова: компьютерно-корпусный подход / под общ. ред. В. И. Заботкиной. - М. : Языки славянской культуры, 2015.-344 с. 
Плунгян, В. А. Корпус как инструмент и как идеология: о некоторых уроках современной корпусной лингвистики / В. А. Плунгян // Русский язык в научном освещении. - 2008. - № 2 (16). - С. 7-20.

Плунгян, В. А. Национальный корпус русского языка: опыт создания корпусов текстов современного русского языка / В. А. Плунгян, Д. В. Сичинава // Труды Международной конференции «Корпусная лингвистика-2004» / под ред. Л. Н. Беляевой [и др.] - СПб. : СПбГУ, 2004. - С. 216-238.

Соловьев, В. Д. Статистические методы анализа диахронических корпусов текстов как инструмент исследования языковой динамики / В. Д. Соловьев // Русский язык: функционирование и развитие : материалы Междунар. науч. конф. (Казань, 18-21 апр. 2012 г.). - Казань : Казанский университет, 2012. - С. 47-52.

Шилихина, К. М. Использование корпусов в исследованиях дискурса / К. М. Шилихина // Вестник Воронежского государственного университета. Серия «Лингвистика и межкультурная коммуникация». - 2014. - № 3. - С. 21-26.

Anthony, L. AntConc (Version 3.4.3) [Computer Software] / L. Anthony. - Tokyo, Japan : Waseda University, 2014. - Electronic data. - Mode of access: http://www.laurenceanthony.net/. - Title from screen.

Corpora in Cognitive Linguistics: Corpus-Based Approaches to Syntax and Lexis (Mouton Select) / ed. by A. Stefanowitsch, S. Th. Gries. - USA : De Gruyter Mouton, 2007. -360 p.

Diachronic Corpora, Genre, and Language Change. Conference, University of Nottingham, April, 8-9, 2016. - Electronic data. - Mode of access: https://www.nottingham.ac.uk/conference/fac-arts/ clas/dcglc/home.aspx. - Title from screen.

Ellis, N. C. Frequency Effects in Language Processing and Acquisition / N. C. Ellis // Studies in Second Language Acquisition. - 2002. - № 24 (2). P. $143-188$.

Gilquin, G. Th. Corpora and Experimental Methods: a State-of-the-art review / G. Th. Gilquin, S. Gries // Corpus Linguistics and Linguistic Theory. 2009. - Vol. 5 (1). - P. 1-26.

Hofmann, S. Corpus Linguistics with BNCweb a Practical Guide (English Corpus linguistics) / S. Hofmann, S. Evert, N. Smith, D. Prytz Lee, Y. Peter Lang. - Frankfurt a/M : Main, 2008. - 288 p.

Ilyinova, E. Yu. Focal Points on Constructing News Stories / E. Yu. Ilyinova, O. S. Volkova // Вестник Волгоградского государственного университета. Серия 2, Языкознание. - 2015. - № 4 (28). - С. 96102. -DOI: http://dx.doi.org/10.15688/jvolsu2.2015.4.11.

Kibrik, A. A. A Corpus Study of Referential Choice: The Role of Rhetorical Structure / A. A. Kibrik, O. N. Krasavina // Компьютерная лингвистика и интеллектуальные технологии = Computational
Linguistics and Intellectual Technology: тр. Междунар. семинара «Диалог'2002» (Протвино, 6-11 июня 2002 г.) : в 2 т. - М. : Наука, 2002. - Т. 1. - С. 561-569.

Kibrik, A. A. Cognitive Structure of Narrative Discourse: the Analysis of Children's Night Dream Stories / A. A. Kibrik, V. I. Podlesskaya, T. M. Kal'kova, A. O. Litvinenko // Компьютерная лингвистика и интеллектуальные технологии = Computational Linguistics and Intellectual Technology: тр. Междунар. семинара «Диалог'2002» (Протвино, 6-11 июня 2002 г.) : в 2 т. - М. : Наука, 2002. - Т. 1. - С. 635-647.

Leech, G. N. Corpora and Theories of Linguistic Performance / G. N. Leech // Directions in Corpus Linguistics // Proceedings of Nobel Symposium 82 (Stockholm, 4-8 August, 1992) / ed. by J. Svartvik. Berlin ; N. Y. : Mouton de Gruyter, 1992. - P. 105-122. McEnery, T. Corpus Linguistics: An Introduction / T. McEnery, A. Wilson. - Edinburgh : University Press, 2001. -316 p.

McEnery, T. Corpus Linguistics: Method, Theory and Practice / T. McEnery, A. Hardy. - Cambridge : Cambridge University Press, 2011. - 301 p.

Meyer, Charles F. English Corpus Linguistics: an Introduction. (Studies in English Language) / Charles F. Meyer. - Cambridge, UK ; N. Y. : Cambridge University Press, 2002. - 168 p.

Stefan, E. Corpora and Collocations / E. Stefan // Corpus Linguistics: An International Handbook, vol. 2 (Handbücher zur Sprach- und Kommunikationswissenschaft (HSK) 29/2) / ed. by A. Lüdeling, M. Kytö. - Berlin ; N. Y. : Mouton De Gruyter, 2009. - P. 1212-1248.

Stubbs, M. British Traditions in Text Analysis: From Firth to Sinclair / M. Stubbs // Text and Technology: In Honour of John Sinclair / ed. by M. Baker, F. Francis, E. Tognini-Bonelli.-Amsterdam ; Philadelphia : John Benjamins, 1993. - P. 1-46.

\section{REFERENCES}

Baranov A.N. Vvedenie $v$ prikladnuyu lingvistiku [Introduction to Applied Linguistics]. Moscow, Editorial URSS Publ., 2003. 360 p.

Boriskina O.O. Korpusnoe issledovanie yazyka: moda ili neobkhodimost? [Corpus Studies of Language: Fashion or Necessity?]. Vestnik Voronezhskogo gosudarstvennogo universiteta. Serija: Lingvistika i mezhkulturnaya kommunikatsiya, 2015, no. 3, pp. 24-27.

Valova E.A., Slyusar N.A. Sravnenie korpusnogo i eksperimentalnogo metoda na primere issledovaniya sintaksicheskikh svoystv enklitiki zhe [Comparison of the Corpus and Experimental Methods on the Example of Studying the Syntactic Properties of zhe Enclitics]. Kompyuternaya lingvistika $i$ intellektualnye 
tekhnologii: po materialam ezhegod. Mezhdunar. konf. "Dialog» (Moskva, 14 iyunya 2014 g.) [Computation Linguistics and Intellectual Technologies: Based on Materials of Dialogue Annual International Conference (Moscow, June 1-4, 2014)]. Moscow, Izd-vo RGGU, 2016, iss. 15 (22), pp. 806-816. URL: http://www.dialog-21.ru/media/3438/ valovaeaslioussarna.pdf.

Vinnik E.I. Funktsionalnaya spetsifika gerundiya $v$ aspekte lingvogenderologii [Functional Specifics of Gerund in the Aspect of Linguistics and Gender Studies]. USA, Saint-Louis, Missouri, Science and Innovation Centre Publishing House, 2016. 202 p.

Golubkova E.E. Diskursivnaya sostavlyayushchaya $v$ issledovaniyakh po kognitivnoy semantike [Discourse Component in Cognitive Semantics Studies]. Vestnik Moskovskogo gosudarstvennogo lingvisticheskogo universiteta, 2012, no. 638, pp.90-98.

Zakharov V.P., Bogdanova S.Yu. Korpusnaya lingvistika [Corpus Linguistics]. Irkutsk, IGLU Publ., 2011. 161 p.

Kibrik A.E. Analiz diskursa v kognitivnoy perspektive: avtoref. dis. ... d-ra filol. nauk [Discourse Analysis in Cognitive Perspective. Dr. philol. sci. abs. diss.]. Moscow, 2003. 90 p.

Kolokolnikova M.Yu. Diskurs-analiz i korpusnyy analiz $\mathrm{v}$ issledovaniyakh $\mathrm{v}$ oblasti istoricheskoy diskursologii [Discourse Analysis and Corpus Analysis in Historical Discourse Studies]. Izvestiya Saratovskogo universiteta. Seriya. Filologiya. Zhurnalistika, 2010, vol. 10, iss. 2, pp. 3-6.

Zabotkina V.I., ed. Metody kognitivnogo analiza semantiki slova: kompyuterno-korpusnyy podkhod [The Methods of Cognitive Analysis of Word Semantics: Computer-Corpus Approach]. Moscow, Yazyki slavyanskoy kultury Publ., 2015. 344 p.

Plungyan V.A. Korpus kak instrument i kak ideologiya: o nekotorykh urokakh sovremennoy korpusnoy lingvistiki [Corpus as a Tool and Ideology: on Some Lessons of Modern Corpus Linguistics]. Russkiy yazyk v nauchnom osveshchenii [The Russian Language and Linguistic Theory], 2008, no. 2 (16), pp. 7-20.

Plungyan V.A., Sichinava D.V. Natsionalnyy korpus russkogo yazyka: opyt sozdaniya korpusov tekstov sovremennogo russkogo yazyka [The Russian Language National Corpus: on Constructing Text Corpus of the Contemporary Russian Language]. Belyaeva L.N., ed. Trudy Mezhdunarodnoy konferentsii «Korpusnaya lingvistika-2004»[Works of the International Conference "Corpus Linguistics-2004"]. Saint Petersburg, SPbGU Publ., 2004, pp. 216-238.

Solovyev V.D. Statisticheskie metody analiza diakhronicheskikh korpusov tekstov kak instrument issledovaniya yazykovoy dinamiki [Statistic Methods of Analyzing Diachronic Corpus of Texts as a Tool of Investigating Language Dynamics]. Russkiy yazyk: funktsionirovanie i razvitie: materialy Mezhdunar. nauch. konf. (Kazan, 18-21 apr. 2012 g.) [The Russian Language: Functioning and Evolution. Materials of International Scientific Conference (Kazan, April 1821, 2012)]. Kazan, Kazanskiy universitet Publ., 2012, pp. 47-52.

Shilikhina K.M. Ispolzovanie korpusov v issledovaniyakh diskursa [On Using Corpus in Discourse Studies]. Vestnik Voronezhskogo gosudarstvennogo universiteta. Seriya «Lingvistika i mezhkulturnaya kommunikatsiya», 2014, no. 3, pp. 21-26.

Anthony L. AntConc (Version 3.4.3) [Computer Software]. Tokyo, Waseda University, 2014. URL: http://www.laurenceanthony.net/.

Stefanowitsch A., Gries S.Th. Corpora in Cognitive Linguistics: Corpus-Based Approaches to Syntax and Lexis (Mouton Select). USA, De Gruyter Mouton, 2007. 360 p.

Diachronic Corpora, Genre, and Language Change. Conference, University of Nottingham, April, 8-9, 2016. URL: https://www.nottingham.ac.uk/ conference/fac-arts/clas/dcglc/home.aspx.

Ellis N.C. Frequency Effects in Language Processing and Acquisition. Studies in Second Language Acquisition, 2002, no. 24 (2), pp. 143-188.

Gilquin G.Th., Gries S. Corpora and Experimental Methods: a State-of-the-art review. Corpus Linguistics and Linguistic Theory, 2009, vol. 5 (1), pp. 1-26.

Hofmann S., Evert S., Smith N., Prytz Lee D., Peter Lang Y. Corpus Linguistics with BNCweb a Practical Guide (English Corpus linguistics). Frankfurt a/M, Main, 2008. 288 p.

Ilyinova E.Yu., Volkova O.S. Focal Points on Constructing News Stories. Vestnik Volgogradskogo gosudarstvennogo universiteta. Seriya 2, Yazykoznanie [Science Journal of Volgograd State University. Linguistics], 2015, no. 4 (28), pp. 96-102. DOI: http://dx.doi.org/10.15688/jvolsu2.2015.4.11.

Kibrik A.A., Krasavina O.N. A Corpus Study of Referential Choice: The Role of Rhetorical Structure. Computational Linguistics and Intellectual Technology: Works of Dialogue2002 International Seminar (Protvino, June 6-11, 2002): in 2 vols. Moscow, Nauka Publ., 2002, vol. 1, pp. 561-569.

Kibrik A.A., Podlesskaya V.I., Kalkova T.M., Litvinenko A.O. Cognitive Structure of Narrative Discourse: the Analysis of Childrens Night Dream Stories. Computational Linguistics and Intellectual Technology: Works of Dialogue2002 International Seminar (Protvino, June 6-11, 2002): in 2 vols. Moscow, Nauka Publ., 2002, vol. 1, pp. 635-647.

Leech G.N. Corpora and Theories of Linguistic Performance. Svartvik J., ed. Directions in Corpus Linguistics. Proceedings of Nobel Symposium 82 
(Stockholm, 4-8 August, 1992). Berlin; New York, Mouton de Gruyter, 1992, pp. 105-122.

McEnery T., Wilson A. Corpus Linguistics: An Introduction. Edinburgh, University Press, 2001.316 p.

McEnery T., Hardy A. Corpus Linguistics: Method, Theory and Practice. Cambridge, Cambridge University Press, 2011. 301 p.

Meyer Ch.F. English Corpus Linguistics: an Introduction (Studies in the English Language). Cambridge, UK; New York, Cambridge University Press, 2002. 168 p.
Stefan E. Corpora and Collocations. Lüdeling A., Kytö M., eds. Corpus Linguistics: An International Handbook, vol. 2 (Handbücher zur Sprach- und Kommunikationswissenschaft (HSK) 29/2). Berlin; New York, Mouton De Gruyter, 2009, pp. 1212-1248.

Stubbs M. British Traditions in Text Analysis: From Firth to Sinclair. Baker M., Francis F., TogniniBonelli E., eds. Text and Technology: In Honour of John Sinclair. Amsterdam; Philadelphia, John Benjamins, 1993, pp. 1-46.

\section{Information About the Authors}

Elena Yu. Ilyinova, Doctor of Sciences (Philology), Professor, Department of English Philology, Volgograd State University, Prosp. Universitetsky, 100, 400062 Volgograd, Russian Federation, ilynov@volsu.ru, english_philolog@mail.ru, http://orcid.org/0000-0002-3310-4020.

Larisa A. Kochetova, Doctor of Sciences (Philology), Associate Professor, Head of Department of English Philology, Volgograd State University, Prosp. Universitetsky, 100, 400062 Volgograd, Russian Federation, kochetova@volsu.ru, english_philolog@mail.ru, http://orcid.org/0000-0002-5278-7373.

\section{Информация об авторах}

Елена Юрьевна Ильинова, доктор филологических наук, профессор кафедры английской филологии, Волгоградский государственный университет, просп. Университетский, 100, 400062 г. Волгоград, Российская Федерация, ilynov@volsu.ru, english_philolog@mail.ru, http://orcid.org/00000002-3310-4020.

Лариса Анатольевна Кочетова, доктор филологических наук, доцент, заведующая кафедрой английской филологии, Волгоградский государственный университет, просп. Университетский, 100, 400062 г. Волгоград, Российская Федерация, kochetova@volsu.ru, english_philolog@mail.ru, http: //orcid.org/0000-0002-5278-7373. 